\section{Editorial}

Check for updates

\title{
Optimal Time of Flu Shot: Influenza B Is the Problem
}

\author{
Dae Sun Jo (iD \\ Department of Pediatrics, Chonbuk National University Medical School, Jeonju, Korea \\ - See the article "Evaluation of Waning Immunity at 6 Months after Both Trivalent and Quadrivalent \\ Influenza Vaccination in Korean Children Aged 6-35 Months” in volume 34, number 46, e279.
}

A trivalent influenza vaccine (TIV) contains hemagglutinin derived from strains of an $\mathrm{A}$ (H3N2)-like virus, an A (H1N1)pdm09-like virus, and a B (either Victoria or Yamagata lineage)-like virus. A quadrivalent influenza vaccine (QIV) contains an additional B strain which is not included in the TIV. On the basis of the experts' review of surveillance data available and their discussion on the candidate vaccine strains, the World Health Organization (WHO) recommends the composition of Northern Hemisphere influenza vaccines, i.e., which strains should be included in the vaccines. ${ }^{1}$ Although the prediction might make a good hit, as the antibody titer wanes and if it is not protective at the time of the epidemic, all the efforts for the influenza vaccination end in failure.

(c) 2019 The Korean Academy of Medical Sciences.

This is an Open Access article distributed under the terms of the Creative Commons Attribution Non-Commercial License (https:// creativecommons.org/licenses/by-nc/4.0/) which permits unrestricted non-commercial use, distribution, and reproduction in any medium, provided the original work is properly cited.

ORCID iD

Dae Sun Jo (iD

https://orcid.org/0000-0002-3141-9539

Disclosure

The author has no potential conflicts of interest to disclose.
Every year, the Korea Centers for Disease Control and Prevention (KCDC) announces when to vaccinate children to prevent influenza. ${ }^{2}$ In addition to when the vaccines are available, the time needed to induce immunity, the duration vaccine-induced immunity maintained, and the expected onset of influenza season should be taken into account to decide the vaccination time. It is more complicated for children under 9 years of age who start their influenza vaccination for the first time, because they are even more vulnerable to the infection and need two shots over an at least 4 week interval. ${ }^{3}$ The article by Lee et al. 4 in this issue provides valuable evidence to relieve the concerns on the timing of vaccination against influenza $\mathrm{A}$ strains. The authors prospectively evaluated the persistence of immunity against influenza strains at 6 months after vaccination in young children and it was favorable against the influenza A strains. On strains of influenza B, however, the results are more perplexing. In this study (targeting the influenza season 2016-2017), all the seroprotection rates for strains $\mathrm{B} /$ Victoria (the lineage included in both TIV and QIV) and B/Yamagata (the lineage included only in the QIV) were below $40 \%$ at 6 months after vaccination, even in the full-dose $(0.5 \mathrm{~mL})$ QIV vaccines. In addition, the authors suggested that the unprimed condition might explain why the immunity was insufficient.

According to the KCDC surveillance data ${ }^{5}$ for the last several influenza seasons, influenza A strains predominated from December to January and influenza B strains followed, and the epidemics persisted until April. Moreover, the lineage of strain B was not infrequently mismatched with that included in the WHO recommended TIV strains. Considering this influenza epidemic trend and the priming effect of the additional B strain, the advantages of 
the QIV as the influenza vaccine for the National Immunization Program should be evaluated, especially in young children. In addition, this approach could widen the optimal time window of influenza vaccination.

\section{REFERENCES}

1. World Health Organization. WHO consultation and information meeting on the composition of influenza virus vaccines for the Northern Hemisphere 2016-2017. https:/www.who.int/influenza/vaccines/virus/ recommendations/consultation201602/en/. Updated 2016. Accessed November 22, 2019.

2. Korea Centers for Disease Control and Prevention. Press release. https://www.cdc.go.kr/board. es? mid=a20501000000\&bid=0015\#. Updated 2019. Accessed November 22, 2019.

3. Choi EH, Park SE, Kim YJ, Jo DS, Kim YK, Eun BW, et al. Recommended immunization schedule for children and adolescents: Committee on Infectious Diseases of the Korean Pediatric Society, 2018. Korean J Pediatr 2019;62(7):252-6. PUBMED | CROSSREF

4. Lee JH, Cho HK, Kim KH, Lee J, Kim YJ, Eun BW, et al. Evaluation of waning immunity at 6 months after both trivalent and quadrivalent influenza vaccination in Korean children aged 6-35 months. J Korean Med Sci 2019;34(46):e279.

CROSSREF

5. Korea Centers for Disease Control and Prevention. Infectious diseases surveillance yearbook 2018 http://www.cdc.go.kr/npt/biz/npp/portal/nppPblctDtaView.do?pblctDtaSeAt=1\&pblctDtaSn=1873. Updated 2019. Accessed November 22, 2019. 